\title{
Word Pairs Delayed Recognition
}

National Cancer Institute

\section{Source}

National Cancer Institute. Word Pairs Delayed Recognition. NCI Thesaurus. Code C120334.

A component of the Children's Memory Scale. A child is read a list of paired words and then asked to say the second word after being told the first. The list is presented three times in this fashion. After about 30 minutes the child is asked whether or not various pairs were on the list. 